\title{
Investigation of Ferrimagnetic Sr-hexaferrite Nanocrystals for Clinical Hyperthermia
}

\author{
Burcu ERTUĞ ${ }^{1 *}$ \\ Nişantaşı University, Faculty of Engineering and Architecture, A ̆gaoğlu Maslak 1453 Sarlyer, Istanbul, 34398, \\ Turkey \\ crossref http://dx.doi.org/10.5755/j02.ms.27566
}

Received 31 August 2020; accepted 16 November 2020

\begin{abstract}
Sr-hexaferrite samples were produced via the conventional ceramic method. X-ray diffractometry (XRD) patterns confirmed the single nanocrystal phase as Sr-hexaferrite (SHF) where any pattern peaks of unreacted $\mathrm{Fe}_{2} \mathrm{O}_{3}$ phase were not detected. The mean crystallite size values were determined to be $44 \pm 3 \mathrm{~nm}$ and $41 \pm 3 \mathrm{~nm}$ for SHF-O1 and SHF-O2, respectively. The chemical bonding peaks of our sample indicated that the structure of Sr-hexaferrite formation was confirmed by FTIR spectra result. Scanning electron microscopy (SEM) images indicated clearly observed porosity regions with relative densities as high as $94 \%$ and $87 \%$ for SHF-O1 and SHF-O2 samples. The vibrating sample magnetometry (VSM) of each sample at $2 \mathrm{~K}$ and under a magnetic field of $10 \mathrm{kOe}$ yielded saturation magnetizations, $M s$ of 93.5 and $94.1 \mathrm{emu} / \mathrm{g}$; remanence values, $\mathrm{Mr}$ of 76.4 and $67.8 \mathrm{emu} / \mathrm{g}$ for SHF-O1 and SHF-O2, respectively. The magnetization loops of both samples indicated a soft ferrimagnetic behaviour in which the saturation magnetizations were higher than those measured at room temperature in the previous studies. The coercivities, Hc were measured to be $150 \mathrm{Oe}$ for both samples. The squareness values, SQR $(\mathrm{Mr} / \mathrm{Ms})$ were measured to be high, approximately 0.82 and 0.72 for SHF$\mathrm{O} 1$ and SHF-O2, respectively. Depending on the adequate values of magnetization an coercivity along with small mean crystallite size and low porosity values of the obtained Sr-hexaferrite samples, we estimate that these samples are likely to be evaluated further for the potential use as thermoseeds in the field of clinical hyperthermia.

Keywords: hexaferrites, ferrimagnetic properties, magnetization, coercivity.
\end{abstract}

\section{INTRODUCTION}

Hexaferrites have been massively fabricated materials and today, their applications involve microwave and radar technology, magnetic recording and data storage, automotive industry and the others [1]. M-type hexaferrites have been examined more frequently than other six classes. $90 \%$ of the magnetic materials that are produced today are based on hexagonal ferrites [2].

The magnetic properties of Sr-hexaferrites such as the saturation magnetization, coercivity have been experimentally studied by replacing $\mathrm{Sr}^{2+}$ and/or $\mathrm{Fe}^{3+}$ sites with cationic dopants [3, 4]. The magnetic measurements at the cryogenic temperature range have initiated in the last twenty years, by the invention of required equipments which are able to work below 4.2K [5].

M-type hexaferrites are metal oxides with a formula of $\mathrm{MFe}_{12} \mathrm{O}_{19}$. They are frequently utilized as permanent magnets [6]. Apart from the high saturation magnetizations and magneto-crystalline anisotropies, also high intrinsic coercivites; they possess a number of electrical properties as well such as high electrical resistivity, low dielectric loss, low eddy current loss etc [7-9]. High frequency and microwave field i.e radar absorbing materials, is an example of their applications. Medical equipment applications also require hard hexaferrite magnets $[10,11]$.

Despite their very old research history, there are still undefined properties of especially M-type hexaferrites. In addition, new and interesting fields of application have been emerging upon the recent studies [12]. Two of the M-type hexaferrites, $\mathrm{BaFe}_{12} \mathrm{O}_{19}$ and $\mathrm{SrFe}_{12} \mathrm{O}_{19}$, exhibit a magnetoplumbite structure. Easy magnetization direction is the c-axis in both of them [13].

Many studies have focused on the electrical and magnetic properties of hard M-type hexaferrites, which have been produced by different synthesis methods such as chemical routes $[14,15]$ and solid oxide reaction methods.

Ferrimagnetic materials are magnetically characterized by magnetometer, often at room temperature. High and low magnetic fields are applied in this characterization; high magnetic fields are utilized particularly for determining the saturation magnetization [16].

Clinical hyperthermia is a thermal treatment of the cancer using ferromagnetic seeds and the application of a magnetic field. Sr-hexaferrites exhibit some tunable magnetic properties, i.e. high saturation magnetization, to be used in this context [17]. Most previous researches have been focused on the room temperature magnetic behaviours of the hexaferrites except some of the very recent studies on the low temperature magnetization [18].

In order to improve the efficiency of the hyperthermia treatment, high saturation magnetization is often preferred [19]. Therefore, the aim of this paper is to conduct the magnetic characterization of Sr-hexaferrites at $2 \mathrm{~K}$ for a higher saturation magnetization in order to enhance the ferrimagnetic properties at the low temperature region.

\footnotetext{
* Corresponding author. Tel.: +90-212-2101010.

E-mail address: burcu.ertug@nisantasi.edu.tr (B. Ertuğ)
} 


\section{EXPERIMENTAL DETAILS}

\subsection{Ferrite preparation}

The polycrystalline Sr-hexaferrites were synthesized using conventional ceramic method. The raw materials of alfa- $\mathrm{Fe}_{2} \mathrm{O}_{3}$ (min 99 wt.\%) and $\mathrm{SrCO}_{3}$ (98-99 wt.\%) were mixed in the appropriate proportion and calcined at $1000{ }^{\circ} \mathrm{C}$ for $1 \mathrm{~h}$ and $2 \mathrm{~h}$ to produce Sr-hexaferrite phase then coded with SHF-O1 and SHF-O2, respectively. Afterwards, the hexaferrite product was ball-milled multiple times inside a hardened steel container with steel balls as the grinding medium to obtain fine powders with mean size of $0.8 \mathrm{~mm}$ in order to achieve a single domain in each powder particle. After mixing with some water, obtained wet slurry was diepressed under the pressure of $5 \mathrm{MPa}$ and the external magnetic field of $10 \mathrm{kOe}$. Then green compacts were fired at $1250{ }^{\circ} \mathrm{C}$ for $1 \mathrm{~h}$.

\subsection{Characterization studies}

\subsubsection{Phase identification}

X-ray diffraction (XRD) data from the sintered samples were collected at angular angles between $20-80^{\circ}$ via Rigaku D-Max2200 diffractometer using CuK $\alpha$ $(\lambda=1.54056 \mathrm{~nm})$ radiation to confirm the phase composition. The mean crystallite size values of the sintered samples were calculated through Debye-Scherrer's formula using the full width at half maximum (FWHM) values obtained from XRD data as in Eq. 1:

$L=\frac{k \cdot \lambda}{\beta \cdot \cos \Theta}$

where $L$ is the average crystallite size; $\beta$ is FWHM; $\Theta$ is the half of the Bragg angle; $\lambda$ is the X-ray wavelength; $k$ is a constant. Based on Bragg's Law, the plane spacing of hexagonal crystal, $d$ is related to the lattice parameters (a and c) as in Eq. 2:

$\frac{1}{d^{2}}=\frac{4}{3} \cdot \frac{h^{2}+h \cdot k+k^{2}}{a^{2}}+\frac{l^{2}}{c^{2}}$.

The lattice parameters of both Sr-hexaferrites were also calculated by Bragg's Law using $d$-spacings and (hkl) indices of the diffraction planes.

\subsubsection{Microstructural characterization}

The bulk densities of the Sr-hexaferrites were calculated by determining the dry weight of the samples after drying in oven for $30 \mathrm{~min}$. and measuring the regular dimensions of both samples. The total porosity for the sintered samples was calculated based on the relative density. The porosities of the samples were also measured by bottle pycnometer method based on the Archimedes principle.

Sr-hexaferrite samples were demagnetized by heating at a rate of $5^{\circ} \mathrm{C} / \mathrm{min}$ up to $460{ }^{\circ} \mathrm{C}$ and were held for $2 \mathrm{~h}$. before the analysis. The sintered samples were surface-finished by polishing with SiC papers. Scanning electron microscopy (SEM) technique was conducted using JEOL-JSM 6060 to examine the microstructural morphology.

\subsubsection{FTIR analysis of hexaferrites}

Fourier transform infrared (ATR-FTIR) spectroscopy results were recorded between the spectra range of $3600-650 \mathrm{~cm}^{-1}$ using Perkin-Elmer Spectrum BX spectrometer in order to confirm the formation of the chemical bonds of the synthesized Sr-hexaferrites.

\subsubsection{Magnetic behaviour of hexaferrites}

To conduct the magnetic characterization of the synthesized Sr-hexaferrites, the magnetization vs. magnetic field curves were recorded at $2 \mathrm{~K}$ under the applied field of 10kOe via vibrating sample magnetometer (VSM) using Cryogenic Limited PPMS.

\section{RESULTS AND DISCUSSION}

\subsection{Microstructural and structural analysis results}

Table 1 indicates the sintered densities of both samples. The theoretical density of $\mathrm{SrFe}_{12} \mathrm{O}_{19}$ was considered to be $5.1 \mathrm{~g} / \mathrm{cm}^{3}$ in order to calculate the percentages of porosity. The resultant relative densities can be derived as $94 \%$ and $87 \%$ for SHF-O1 and SHF-O2 samples.

Table 1. Densities of Sr-hexaferrite samples

\begin{tabular}{|l|c|c|c|c|c|}
\hline Sample & $\varnothing, \mathrm{mm}$ & $t, \mathrm{~mm}$ & $\rho, \mathrm{g} / \mathrm{cm}^{3}$ & $\mathrm{Pi}, \%$ & Pii, \% \\
\hline SHF-O1 & 10 & 5 & 4.78 & 6 & 2.94 \\
\hline SHF-O2 & 6 & 3 & 4.44 & 13 & 13 \\
\hline$\varnothing$ : diameter, t: thickness $\rho$ : bulk density, \\
Pi: porosity by dimensions, Pii: porosity by pycnometer \\
\hline
\end{tabular}

SEM images of SHF-O1 and SHF-O2 samples are given in Fig. 1. Grain boundaries were not evident even after highmagnification microscopic examination. Thus the grain morphologies were not observed. However, the porosity regions were clearly observed for both samples.

Fig. 2 indicates the XRD pattern peaks of sintered SHF$\mathrm{O} 1$ and SHF-O2 samples. XRD results confirmed the single nanocrystal phase as magnetoplumbite Sr-hexaferrite (JCPDS card number 00-024-1207) in both samples. The pattern peaks of unreacted $\mathrm{Fe}_{2} \mathrm{O}_{3}$ phase were not detected.

The crystallite size values from the highest to lowest peak intensity were measured as $43.1 \mathrm{~nm}, 41.38 \mathrm{~nm}$, $47.89 \mathrm{~nm}$ for SHF-O1 and $43.32 \mathrm{~nm}, 37.48 \mathrm{~nm}, 42.81 \mathrm{~nm}$ for SHF-O2, corresponding to the peaks of (107), (114) and (110). According to the results, the crystallites along $<110>$ directions were higher than those along $<114>$ directions, which indicate a platelet growth in the Sr-hexaferrite crystals [20].

The lattice parameters (a, c) of Sr-hexaferrite crystal were calculated as $6.16 \mathrm{~A}^{\circ}, 23.7 \mathrm{~A}^{\circ}$ for SHF-O1 and $6.16 \mathrm{~A}^{\circ}, 23.55 \mathrm{~A}^{\circ}$ for SHF-O2, respectively.

\subsection{FTIR results}

In order to confirm the formation of Sr-hexaferrite, FTIR spectrum of SHF-O1 sample was examined (Fig. 3). First, since the band range of $3451-3498 \mathrm{~cm}^{-1}$ is related to the stretching of water molecules [21], the small band at $3492 \mathrm{~cm}^{-1}$ in our sample corresponds to the band of $\mathrm{O}=\mathrm{H}$. The sharp peak at $2920 \mathrm{~cm}^{-1}$ indicates the surface bending bond of the hydoxide $(-\mathrm{OH})$ group due to the damped environment [22]. 


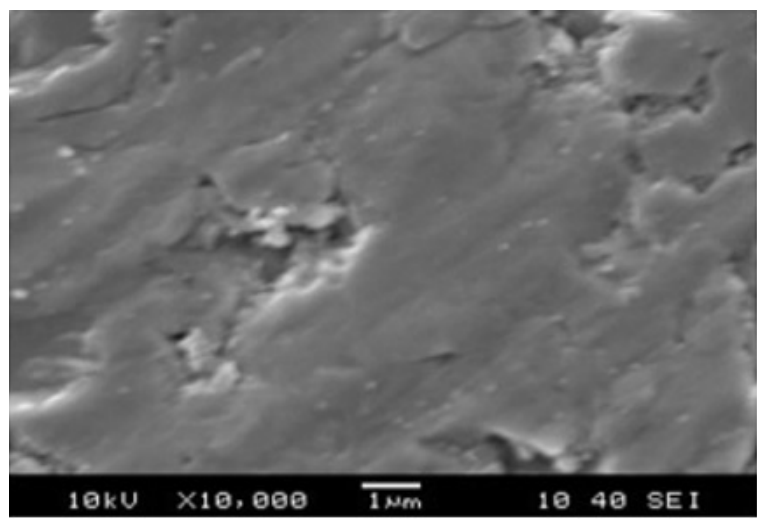

Fig. 1. SEM images of both samples: $a-S H F-O 1 ; b-S H F-O 2$

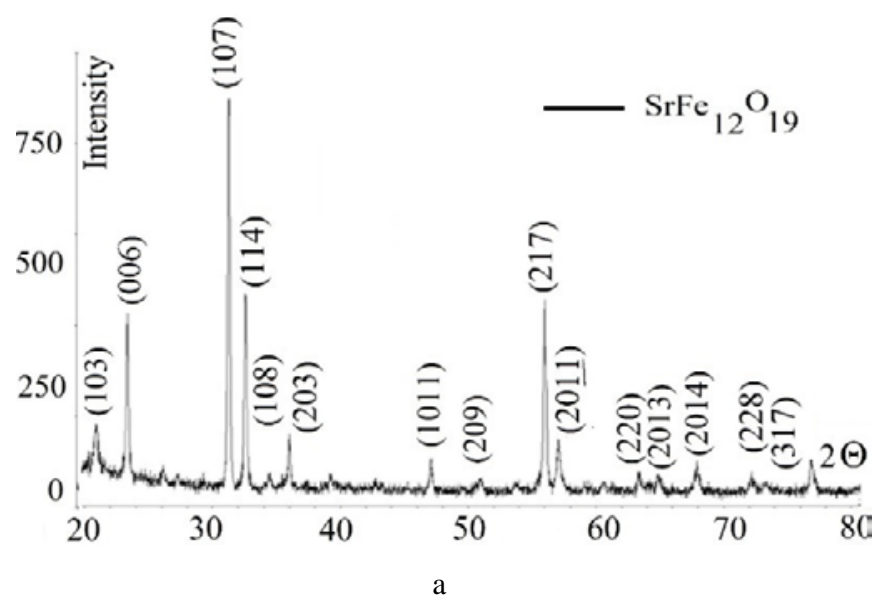

Fig. 2. XRD patterns of both samples: a-SHF-O1; b-SHF-O2

The small peaks around $1722 \mathrm{~cm}^{-1}$ show the stretching in the vibration of $\mathrm{C}=\mathrm{O}$ bond, whereas the relatively stronger small band at $1065 \mathrm{~cm}^{-1}$ corresponds to the C-O bond stretching. Finally, the clear sharp peak at $797 \mathrm{~cm}^{-1}$ is related to metal oxide stretching of vibration [21].

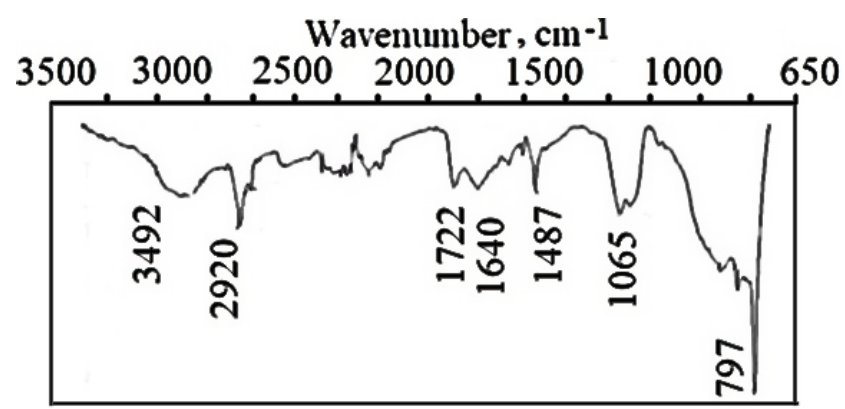

Fig. 3. FTIR spectrum of the sample of SHF-O1

As a result, the chemical bonding peaks of our sample indicated that the structure of Sr-hexaferrite formation was confirmed by FTIR spectra result.

\subsection{Magnetic behaviour results}

According to magnetic measurements at $2 \mathrm{~K}$, it was confirmed that both samples exhibit typical soft ferrimagnetic behaviour as shown by the narrow hysteresis curves in Fig. 4. The magnetic alteration from hard to soft

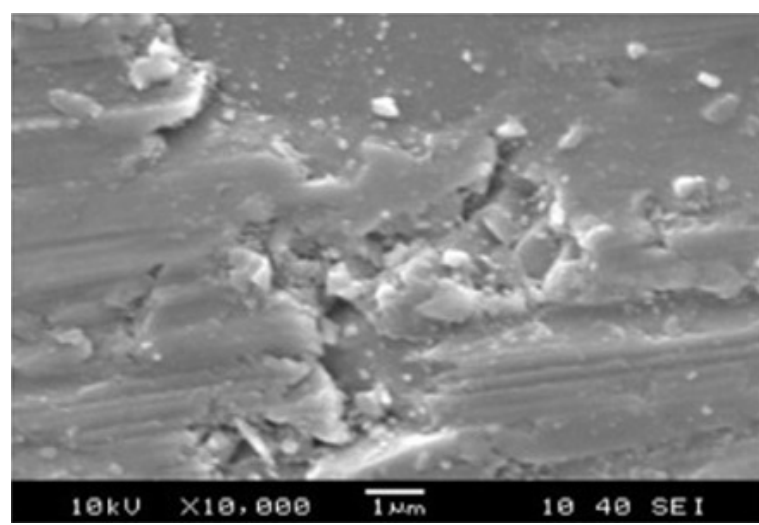

b

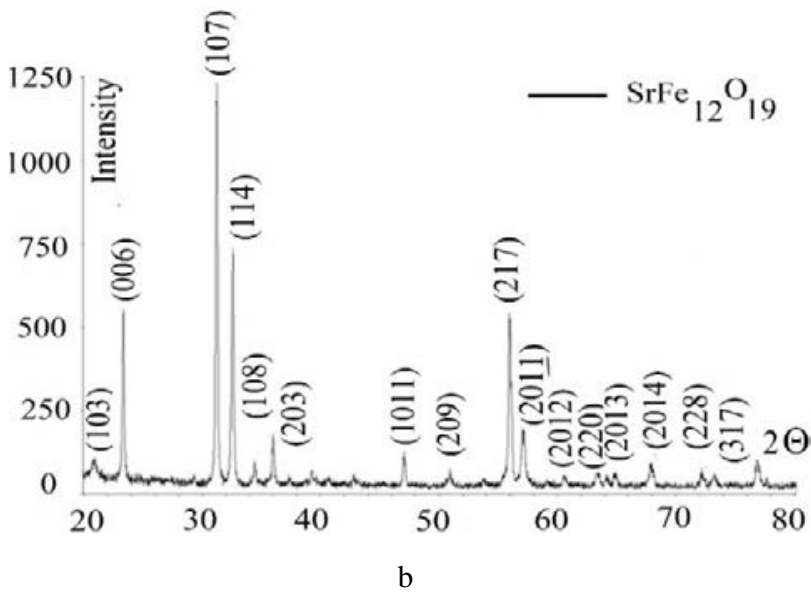

type in the ferrimagnetic hexaferrites, where spins are noncollinear is a function of measurement temperature [23].

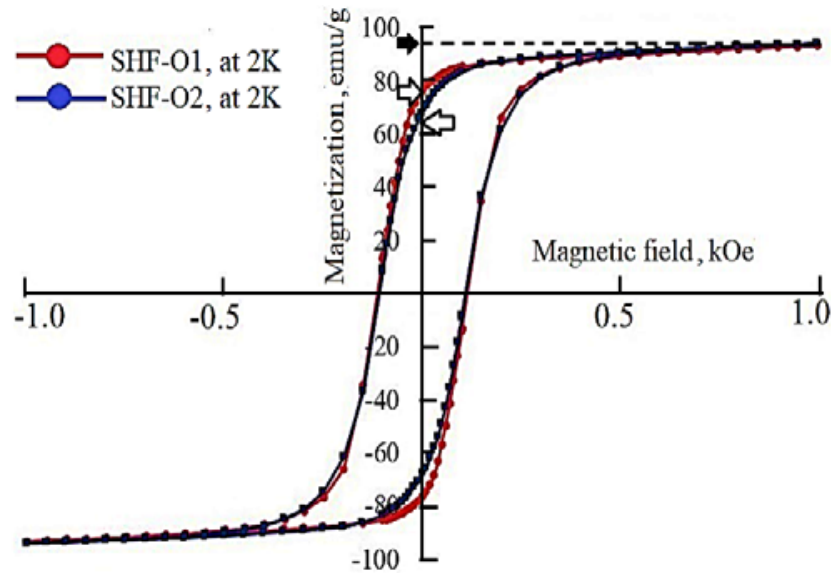

Fig. 4. M-H hysteresis loops of the samples: a-SHF-O1; b-SHF-O2. Full arrow: saturation and blank arrow: remanence values

The magnetic parameters of two Sr-hexaferrite samples were calculated from the low temperature $\mathrm{M}-\mathrm{H}$ curves. The saturation magnetizations, Ms were determined to be 93.5 and $94.1 \mathrm{emu} / \mathrm{g}$ for SHF-O1 and SHF-O2, respectively at $2 \mathrm{~K}$. These values were higher than those measured at the room temperature [12]. 


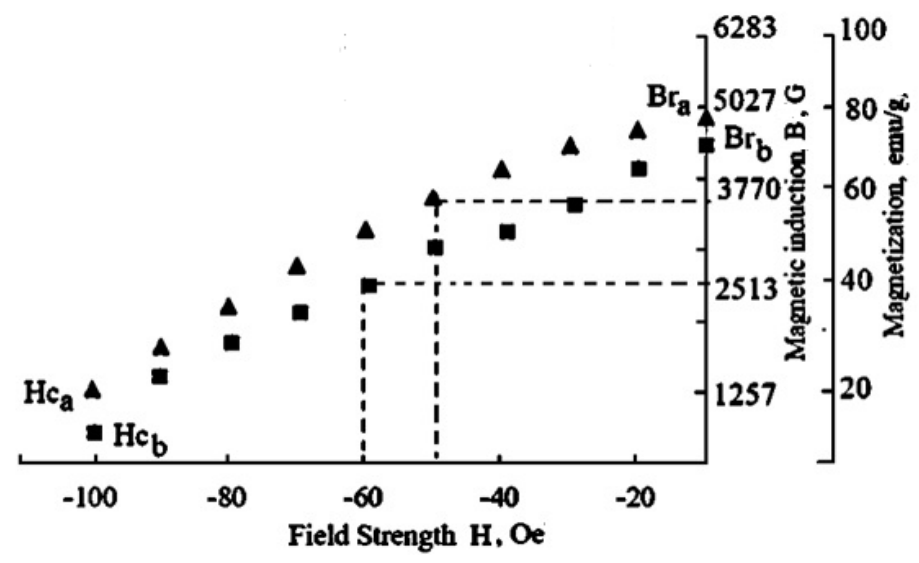

a

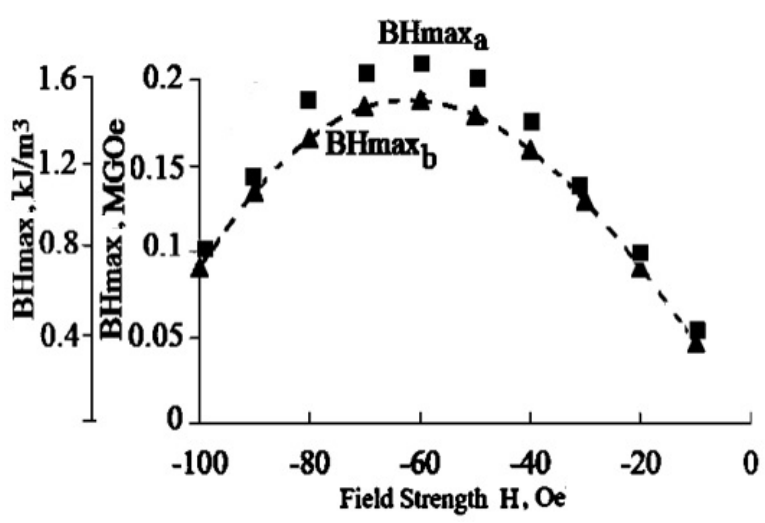

b

Fig. 5. a-demagnetization curves; b-BHmax parabola of Sr-hexaferrite samples

Because a less thermal energy causes a small fluctuation in the magnetic moments thus, the saturation magnetization rises [12]. Remanence values, $\mathrm{Mr}$ were determined to be 76.4 and $67.8 \mathrm{emu} / \mathrm{g}$ for SHF-O1 and SHF-O2, respectively. Remanence values of the Sr-hexaferrites at the room temperature in the previous studies were substantially lower, $13.2 \mathrm{emu} / \mathrm{g}$ in comparison [13] due to canted type spin structures in the ferrimagnetic hexaferrites. The coercivities, Hc at $2 \mathrm{~K}$ were measured to be $150 \mathrm{Oe}$ for both SHF-O1 and SHF-O2 samples which were significantly lower in comparison to those at room temperature [13], typical of M-type hexaferrites.

At $2 \mathrm{~K}$ the squareness values, SQR $(\mathrm{Mr} / \mathrm{Ms})$ were measured to be high, approximately 0.82 and 0.72 for SHF$\mathrm{O} 1$ and SHF-O2, respectively.

These results can be attributed to the appropriate sintering treatment which permitted to obtain an oriented Srhexaferrite [24]. Instead, the room temperature SQR values were lower, i.e 0.54 for Sr-hexaferrite [13] because the spin canting causes a reduced remanence in the hexaferrites [12]. The mean crystallite size values of $44 \pm 3 \mathrm{~nm}$ and $41 \pm 3 \mathrm{~nm}$ for SHF-O1 and SHF-O2, respectively were calculated to be smaller than the critical value for a single-domain $(650 \mathrm{~nm})$ of the Sr-hexaferrites [25].
Table 2 indicates the magnetic behaviour results of Srhexaferrites were given at $2 \mathrm{~K}, 10 \mathrm{~K}$ and $300 \mathrm{~K}$. The saturation magnetization value, Ms of our sample at $2 \mathrm{~K}$ was close to that of Tm doped SHF measured at $10 \mathrm{~K}$ but it was lower than BHF value measured at $2 \mathrm{~K}$. On the contrary, the coercivity, Hc of our sample at $2 \mathrm{~K}$ was lower in comparison to the values obtained in other studies both at $300 \mathrm{~K}$ and $10 \mathrm{~K}$, which can be attributed to the variations in the crystalline size. In order to examine the demagnetization behaviour of the samples, the second quadrant of the ferrimagnetic curve was converted into the magnetic induction $(B)$ vs. field strength $(H)$ graph as in Fig. 5 a. The remanent induction $\mathrm{Br})$ and the coercivity $(\mathrm{HC})$ values of the Sr-hexaferrites were shown on the $B-H$ graph.

On the second quadrant of the ferrimagnetic curve, the largest rectangle was also drawn to determine the maximum energy product, $B H$ max of our sample as shown in Fig. 5 a. The parabola curve in Fig. $5 \mathrm{~b}$ indicates the maximum energy product vs field strength. In order to draw this curve, the combinations of $\mathrm{M}-\mathrm{H}$ values in the second quadrant were considered. The vertex of this curve was taken as the BHmax of our sample. BHmax values were calculated to be 1.6 and $1.2 \mathrm{~kJ} \cdot \mathrm{m}^{-3}(0.19$ and $0.16 \mathrm{MGOe})$ for SHF-O1 and SHF-O2, respectively.

Table 2. Magnetic behaviour of the Sr-hexaferrite samples

\begin{tabular}{|c|c|c|c|c|c|}
\hline Magnetic properties & Temperature & $\mathrm{BHF}(\mathrm{Ce}, \mathrm{Zn})^{\mathrm{a}-\mathrm{b}}$ & SHF(Tm) & $\mathrm{SHF}(\mathrm{Zr})$ & SHF-O1 \\
\hline \multirow{3}{*}{ Ms, emu/g } & $300 \mathrm{~K}$ & $65(67)$ & 70 & 52 & $46^{+}$ \\
\hline & $2 \mathrm{~K}$ & $117(117)$ & - & - & 93 \\
\hline & $10 \mathrm{~K}$ & - & 97 & 75 & - \\
\hline \multirow{3}{*}{$\mathrm{Mr}, \mathrm{emu} / \mathrm{g}$} & $300 \mathrm{~K}$ & $18(7)$ & 41 & 25 & $22^{+}$ \\
\hline & $2 \mathrm{~K}$ & $10(6)$ & - & - & 76 \\
\hline & $10 \mathrm{~K}$ & - & 54 & 37 & - \\
\hline \multirow{3}{*}{ Hc, kOe } & $300 \mathrm{~K}$ & $7.5(3.1)$ & 4.3 & 4.5 & $8.8^{+}$ \\
\hline & $2 \mathrm{~K}$ & $2.3(1.5)$ & - & - & 0.2 \\
\hline & $10 \mathrm{~K}$ & - & 2.8 & 3.5 & - \\
\hline \multirow{3}{*}{$\mathrm{Mr} / \mathrm{Ms}$} & $300 \mathrm{~K}$ & $0.3(0.1)$ & 0.6 & 0.5 & $0.5^{+}$ \\
\hline & $2 \mathrm{~K}$ & $0.1(0.1)$ & - & - & 0.8 \\
\hline & $10 \mathrm{~K}$ & - & 0.6 & 0.5 & - \\
\hline \multicolumn{2}{|c|}{ Reference } & [26] & [27] & [28] & Present study, [18] \\
\hline
\end{tabular}


Heating effect generated by the ferromagnetism is a significant point in the clinical hyperthermia application. Specific absorption rate (SAR) is a measure of the heating effect and this parameter has been investigated by some of the researchers for Sr-hexaferrite. SAR value of $0.5-0.7 \mathrm{~W} / \mathrm{g}$ has been found in Sr-hexaferrite composites at a frequency of $214 \mathrm{kHz}$ and amplitude of 22Oe, which shows some potential usage in the clinical hyperthermia [29]. SAR values between couple of units and tens W/g have been measured in Sr-hexaferrite/maghemite nanocomposites at a frequency of $108 \mathrm{kHz}$ and amplitude of $188-855$ Oe [30]. SAR values in the range of $50-750 \mathrm{~W} / \mathrm{g}$ have been determined in $\mathrm{Fe}_{3} \mathrm{O}_{4}$ nano-particles at a frequency of $265 \mathrm{kHz}$ and amplitudes of 184-625 Oe depending on the particle size [31]. Also, some nano-spinel ferrites of $\mathrm{MgFe}_{2} \mathrm{O}_{4}, \quad \mathrm{Zn}_{\mathrm{x}} \mathrm{Fe}_{3-\mathrm{x}} \mathrm{O}_{4}, \quad \mathrm{MnZnFe}_{2} \mathrm{O}_{4}$ have also been investigated for their SAR values and they have been measured to be 3.9, 36 and $110 \mathrm{~W} / \mathrm{g}$, respectively for these ferrites [31]. As a result, it is estimated that our Srhexaferrite ferrimagnets may produce similar orders of heating effect to be used in the clinical hyperthernmia. Thus, it will be quite beneficial to test the heating effects of our Sr-hexaferrite samples for future studies.

\section{CONCLUSIONS}

Sr-hexaferrites were successfully synthesized via the conventional sintering. As-sintered densities and the porosities determined indicated a low porosity content. This was confirmed by SEM images of both samples. However, the grain boundaries could not be observed in the SEM microscopy due to nano-sized crystals. XRD was utilized to ensure the phase purity and the patterns indicated that both of the samples contained a single phase of Sr-hexaferrite. The crystallite size values calculated by Debye-Scherrer's formula varied in the range of $37-47 \mathrm{~nm}$.

Magnetic behaviour of the Sr-hexaferrite samples altered from hard to soft ferrimagnetism with the decreasing temperature in comparison to the previous studies where the room-temperature magnetization was determined. In contrast to the room-temperature studies, the collinear type of magnetic structure is present at $2 \mathrm{~K}$ with an increase in the magnetization values. The saturation magnetization increased by $1.1 \%$ when the samples of SHF-O1 and SHF$\mathrm{O} 2$ were compared due to the higher XRD intensity observed in SHF-O2. The coercivities of both samples at $2 \mathrm{~K}$ were measured to be 1500 e, which can be attributed to the close crystal size values in the samples.

Consequently, it is anticipated that the performance of our Sr-hexaferrite nanocrystals with a number of appreciable properties might be useful as ferrimagnetic thermoseeds for clinical hyperthermia applications, where a combination of high magnetization and low coercivity is required.

\section{Acknowledgments}

The author is thankful to Mr. Haluk Gürses at Dokuz Eylül University for his SEM and XRD analysis work in the study. The vibrating sample magnetometer (VSM) measurements were conducted by Middle East Technical University (METU), Central Laboratory, Ankara.

\section{REFERENCES}

1. Al-Hwaitata, E.S., Hussein, M.A., Bsoul, I., Buqain, R.A., Mahmood, S.H. Synthesis, Structural and Magnetic Properties of $\mathrm{Ba}_{3}\left(\mathrm{Zn}_{\mathrm{x}} \mathrm{Mg}_{1-\mathrm{x}}\right)_{2} \mathrm{Fe}_{24} \mathrm{O}_{41}$ Z-Type Hexaferrites Acta Physica Polonica A 136 (3) 2019: pp. 548-554. https://doi.org/10.12693/APhysPolA.136.548

2. Pullar, R.C. Hexagonal ferrites: A Review of the Synthesis, Properties and Applications of Hexaferrite Ceramics Progress in Materials Science 57 (7) 2012: pp. 1191-1334. https://doi.org/10.1016/j.pmatsci.2012.04.001

3. Singh, V.P., $\quad$ Jasrotia, R., $\quad$ Kumar, R., $\quad$ Raizada, P., Thakur, S., Batoo, K.M., Singh, M.A. Current Review on the Synthesis and Magnetic Properties of M-Type Hexaferrites Material World Journal of Condensed Matter Physics 8 2018: pp. 36-61.

https://doi.org/10.4236/wjcmp.2018.82004

4. Al Dairy, A.R., Al-Hmoud, L.A., Khatatbeh, H.A. Magnetic and Structural Properties of Barium Hexaferrite Nanoparticles Doped with Titanium Symmetry $11(732)$ 2019: pp. $1-12$. https://doi.org/10.3390/sym11060732

5. Kosterov, A. Magnetic Properties, Low-Temperature. In: Gubbins D.Herrero-Bervera E. (eds) Encyclopedia of Geomagnetism and Paleomagnetism. Springer, Dordrecht, 2007: pp. 515-516.

6. Sanida, A., Stavropoulos, S.G., Speliotis, Th., Psarras, G.C. Magnetic Nanoparticles-Polymer Matrix Nanodielectrics: Manufacturing, Characterization and Functionality Materials Today: Proceedings 5 (14) 2018: pp. 27491-27499.

https://doi.org/10.1016/j.matpr.2018.09.068

7. Auwal, I.A., $\quad$ Erdemi, H., Sözeri, H., Güngüneş, H., Baykal, A. Magnetic and Dielectric Properties of $\mathrm{Bi}^{3+}$ Substituted $\mathrm{SrFe}_{12} \mathrm{O}_{19}$ Hexaferrite Journal of Magnetism and Magnetic Materials 412 2016: pp. 69-82. https://doi.org/10.1016/j.jmmm.2016.03.066

8. Carol, T.T.T., Mohammed, J., Bhat, B.H., Mishra, S., Godara, S.K., Srivastava, A.K. Effect of Cr-Bi Substitution on the Structural, Optical, Electrical and Magnetic Properties of Strontium Hexaferrites Physica B:Condensed Matter 575 2019: pp. 411681. https://doi.org/10.1016/j.physb.2019.411681

9. Chauhan, C.C., Kagdi, A.R., Jotania, R.B., Upadhyay, A., Sandhu, C.S., Shirsath, S.E., Meena, S.S. Structural, Magnetic and Dielectric Properties of Co-Zr Substituted Mtype Calcium Hexagonal Ferrite Nanoparticles in the Presence of $\alpha-\mathrm{Fe}_{2} \mathrm{O}_{3}$ Phase Ceramics International 44 (15) 2018: pp. $17812-17823$.

https://doi.org/10.1016/j.ceramint.2018.06.249

10. Hilczer, A., Pasińska, K., Andrzejewski, B., Matczak, M., Pietraszko, A. Magnetic Properties of $\mathrm{Sr}_{0.95} \mathrm{Nd}_{0.05} \mathrm{Fe}_{12}$ ${ }_{x} \mathrm{Sc}_{\mathrm{x}} \mathrm{O}_{19}$ Hexaferrite Nanocrystals: (Tcone, H, x) Phase Diagram Ceramics International 45 (1) 2019: pp. $1189-1195$. https://doi.org/10.1016/j.ceramint.2018.09.303

11. Najafinezhad, A., Abdellahi, M., Saber-Samandari, S., Ghayour, H., Khandan, A. Hydroxyapatite-M-type Strontium Hexaferrite: A New Composite for Hyperthermia Applications Journal of Alloys and Compounds 73415 2018: pp. 290-300. https://doi.org/10.1016/j.jallcom.2017.10.138

12. Almessiere, M.A., Slimani, Y., ElSayed, H.S., Baykal, A. Morphology and Magnetic Traits of Strontium Nanohexaferrites: Effects of Manganese/Yttrium Co- 
substitution Journal of Rare Earths 37 (7) 2019: pp. $732-740$.

https://doi.org/10.1016/j.jre.2018.09.014

13. Malhotra, S., Chitkara, M., Sandhu, I.S., Dawar, N., Singh, J. Investigation of Structural, Magnetic and Dielectric Properties of Terbium Doped Strontium Hexaferrite for High Frequency Applications Indian Journal of Science and Technology 9 (27) 2016: pp. 1-9. https://doi.org/10.17485/ijst/2016/v9i27/96638

14. Amir, M., Sozeri, H., $\quad$ Korkmaz, A., Baykal, A. Concentration and Temperature-Dependent Magnetic Properties of $\mathrm{Ba}_{1-\mathrm{x}} \mathrm{Zn}_{\mathrm{x}} \mathrm{Fe}_{12} \mathrm{O}_{19}$ Hexaferrites Ceramics International 44 2018: pp. 988-992.

https://doi.org/10.1016/j.ceramint.2017.10.033

15. Auwal, I.A., Baykal, A., Güner, S., Sözeri, H. Magnetooptical Properties of $\mathrm{SrBi}_{x} \mathrm{La}_{x} \mathrm{Fe}_{12-2 \times} \mathrm{O}_{19}(0.0 \leq \mathrm{x} \leq 0.5)$ Hexaferrites by Sol-Gel Auto-combustion Technique Ceramics International 43 (1) 2017: pp. 1298-1303. https://doi.org/10.1016/j.ceramint.2016.10.080

16. Arabyazdi, S., Yazdanpanah, A., Hamedani, A., Ramedani, A., Moztarzadeh, F. Synthesis and Characterization of $\mathrm{CaO}-\mathrm{P}_{2} \mathrm{O}_{5}-\mathrm{SiO}_{2}-\mathrm{Li}_{2} \mathrm{O}-\mathrm{Fe}_{2} \mathrm{O}_{3}$ Bioactive Glasses: The Effect of $\mathrm{Li}_{2} \mathrm{O}-\mathrm{Fe}_{2} \mathrm{O}_{3}$ Content on the Structure and in-vitro Bioactivity Journal of Non-Crystalline Solids 503-504 2019: pp. 139-150.

https://doi.org/10.1016/j.jnoncrysol.2018.09.040

17. Ur Rashid, A., Southern, P., $\quad$ Darr, J.A., Awan, S., Manzoor, S. Strontium Hexaferrite $\left(\mathrm{SrFe}_{12} \mathrm{O}_{19}\right)$ based Composites for Hyperthermia Applications Journal of Magnetism and Magnetic Materials 344 2013: pp. $134-139$. http://dx.doi.org/10.1016/j.jmmm.2013.05.048

18. Al-Garalleh, G.A., Mahmood, S.H., Bsoul, I., Loloee, R. Structural and Magnetic Properties of RE-Al Substituted Nanocrystalline Hexaferrites $\left(\mathrm{Sr}_{1-\mathrm{x}} \mathrm{RE}_{\mathrm{x}} \mathrm{Al}_{2} \mathrm{Fe}_{10} \mathrm{O}_{19}\right)$ Materials Research Express 7 2020: pp. 026103. https://doi.org/10.1088/2053-1591/ab5ddd

19. Thomas, L.A. Nanoparticle Synthesis For Magnetic Hyperthermia Ph.D. Thesis University College London 2010.

20. Mahmood, S.H., $\quad$ Awadallah, A.M., $\quad$ Bsoul, I., Maswadeh, Y. Structural and Magnetic Properties of Lightly doped M-type Hexaferrites arXiv preprint arXiv:1707.04709 2017: pp. 1-20.

21. Gayathri, S., Jesurani, S., Ashok, K., John, P.A. Structural and Magnetic Properties of Nb-Zn doped Barium Strontium Nanocomposite Powder Prepared by Sol-gel Method International Journal of Current Research 10 (06) 2018: pp. 70066-70073. https://doi.org/10.21474/IJAR01/7098

22. Ramay, S.M., Atiq, S., Saleem, M., Mahmood, A., Siddiqi, S.A., Naseem, S., Al-Zeghayer, Y., Alzayed, N.S.
Shahabuddin, M. Enhanced Magnetization of Sol-Gel Synthesized Pb-Doped Strontium Hexaferrites Nanocrystallites at Low Temperature Journal of Nanomaterials 452468 2014: pp. 1-7. https://doi.org/10.1155/2014/452468

23. Hobbs, D., Hafner, J. Noncollinear Magnetism Annals of the Marie Curie Fellowship Association 4 2006: pp. 1-6.

24. Liu, Q., Wu, C., Wang, Y., Zhou, L., Li, J., Liu, Y., Zhang, H. Textured M-type Barium Hexaferrite $\mathrm{Ba}(\mathrm{ZnSn})_{\mathrm{x}} \mathrm{Fe}_{12-2 \times \mathrm{O}_{19}}$ with c-axis Anisotropy and High Squareness Ratio Ceramics International 45 (4) 2019: pp. $4535-4539$. https://doi.org/10.1016/j.ceramint.2018.11.138

25. Jing, P., Du, J., Wang, J., Wei, J., Pan, L., Li, J., Liu, Q. Width-controlled M-type Hexagonal Strontium Ferrite $\left(\mathrm{SrFe}_{12} \mathrm{O}_{19}\right)$ Nanoribbons with High Saturation Magnetization and Superior Coercivity Synthesized by Electrospinning Science Reports 5 2015: pp. 1-10. https://doi.org/10.1038/srep15089

26. Tanwar, K., Gyan, D.S., Gupta, P., Pandey, S., Kumar, O, Kumar, D. Investigation of Crystal Structure, Microstructure and Low Temperature Magnetic Behavior of Ce4+ and Zn2+ co-doped Barium Hexaferrites (BaFe12O19) RSC Advances 8 2018: pp. 19600. https://doi.org/10.1039/c8ra02455c

27. Almessiere, M.A., Slimani, Y., Gungunes, H., Manikandan, A., Baykal, A. Investigation of the Effects of Tm3+ on the Structural, Microstructural, Optical, and Magnetic Properties of Sr Hexaferrites Results in Physics 13 2019: pp. 102166. https://doi.org/10.1016/j.rinp.2019.102166

28. Almessiere, M.A., Slimani, Y., Sertkold, M., Nawaz, M., Baykal, A., Ercan, I. The Impact of $\mathrm{Zr}$ substituted $\mathrm{Sr}$ Hexaferrite: Investigation on Structure, Optic and Magnetic Properties Results in Physics 13 2019: pp. 102244. https://doi.org/10.1016/j.rinp.2019.102244

29. Rashid, A.U., $\quad$ Southern, P., $\quad$ Darr, J.A., $\quad$ Awan, S., Manzoor, S.Strontium Hexaferrite Based Composites For Hyperthermia Applications Journal of Magnetism and Magnetic Materials 344 2013: pp. 134-139. https://doi.org/10.1016/j.jmmm.2013.05.048

30. Veverka, P., $\quad$ Pollert, E., $\quad$ Zaveta, K., $\quad$ Vasseur, S., Duguet, E. Sr-hexaferrite/Maghemite Composite Nanoparticles-Possible New Mediators For Magnetic Hyperthermia Nanotechnology 19 (21) 2008: pp. 215705. https://doi.org/10.1088/0957-4484/19/21/215705

31. Mohapatra, J., Xing, M., Liu, J.P. Inductive Thermal Effect of Ferrite Magnetic Nanoparticles Materials 12 (3208) 2019: pp. $1-30$. https://doi.org/10.3390/ma12193208

(c) Ertuğ 2021 Open Access This article is distributed under the terms of the Creative Commons Attribution 4.0 International License (http://creativecommons.org/licenses/by/4.0/), which permits unrestricted use, distribution, and reproduction in any medium, provided you give appropriate credit to the original author(s) and the source, provide a link to the Creative Commons license, and indicate if changes were made. 